\title{
Advanced Glycosylation Endproducts Block the Antiproliferative Effect of Nitric Oxide

\author{
Role in the Vascular and Renal Complications of Diabetes Mellitus
}

Margaret Hogan, Anthony Cerami, and Richard Bucala

The Picower Institute for Medical Research, Manhasset, New York 11030

\begin{abstract}
Advanced glycosylation endproducts (AGEs) accumulate on long-lived tissue proteins such as basement membrane collagen and have been implicated in many of the long-term complications of diabetes mellitus. These products originate from glucose-derived Schiff base and Amadori products but undergo a series of complex rearrangement reactions to form ultimately protein-bound, fluorescent heterocycles. AGEs can react with and chemically inactivate nitric oxide (NO), a potent endothelial cell-derived vasodilator and antiproliferative factor. Since mesenchymal cell proliferation is an early and characteristic lesion of diabetic vasculopathy and glomerulopathy, we investigated the possibility that collagen-bound AGEs functionally inactivate the antiproliferative effect of NO. In model cell culture systems, AGEs were found to block the cytostatic effect of NO on aortic smooth muscle and renal mesangial cells. The inactivation of endothelial cell-derived NO by basement membrane AGEs may represent a common pathway in the development of the accelerated vascular and renal disease that accompany long-term diabetes mellitus. (J. Clin. Invest. 1992. 90:1110-1115.) Key words: endothelium • atherosclerosis • glycation $\cdot$ glomerulopathy $\bullet$ mesangium
\end{abstract}

\section{Introduction}

Circulating sugars such as glucose react nonenzymatically with proteins to initiate a posttranslational modification process known as advanced glycosylation (1-3). Glucose reacts with the amino groups of proteins to form first reversible Schiff base and Amadori products. These adducts then undergo further reactions to form a heterogeneous group of fluorescent, protein-bound moieties called advanced glycosylation endproducts, or AGEs. ${ }^{1}$ These products remain irreversibly bound to

This paper was presented in part at the Third International Symposium on Hypertension Associated with Diabetes Mellitus held in Boston, MA, 21-23 November 1991.

Address correspondence to Richard Bucala, The Picower Institute for Medical Research, 350 Community Drive, Manhasset, NY 11030. 1992.

Received for publication 2 April 1992 and in revised form 22 May

1. Abbreviations used in this paper: AGEs, advanced glycosylation endproducts; NO, nitric oxide; SNAP, $S$-nitroso- $N$-acetyl-D,L-penicillinamine.

J. Clin. Invest.

(C) The American Society for Clinical Investigation, Inc.

$0021-9738 / 92 / 09 / 1110 / 06 \$ 2.00$

Volume 90, September 1992, 1110-1115 tissue proteins and accumulate in increased amounts in patients with diabetes mellitus. The progressive accumulation of AGEs, particularly on long-lived basement membrane proteins, has been implicated in the pathogenesis of a number of the long-term complications of diabetes mellitus (2).

Vascular tone and regional blood flow are mediated in part by the soluble products of endothelial cells (4). An important mediator of these responses is nitric oxide (NO), a radical species produced enzymatically by endothelial cells after stimulation by such factors as acetylcholine, histamine, and increased flow (5-7). Although NO possesses an in vivo half-life of less than a few seconds, it rapidly traverses the subendothelial space to activate smooth muscle cell guanylate cyclase, leading to smooth muscle relaxation and vasodilatation.

In addition to its role in regulating vascular tone, NO exerts potent homeostatic and antiproliferative effects on different cell types (7-10). Nitric oxide is released tonically by vascular endothelial cells $(11,12)$ and may serve to maintain the mitogenic quiescence of subintimal mesenchymal cells (9). In atherosclerosis, vascular smooth muscle cell proliferation is an early and characteristic abnormality (13). It has been postulated that the removal of locally produced NO, as occurs after endothelial injury, might be an early, initiating event in the development of the atherosclerotic vascular lesion (9).

Recent studies have shown that protein-bound AGEs can react with and inactivate NO via a direct chemical reaction (14). Advanced glycosylation endproducts form continuously in the subendothelial space that separates endothelium from vascular smooth muscle $(2,3)$. The inactivation of NO by AGEs may play a role in the defective vasodilatory responses that occur in diabetes mellitus. In animals with experimentally induced diabetes, defective vasodilatation occurs over a time period that approximates the time course of AGE formation (14). The administration of aminoguanidine, an inhibitor of advanced glycosylation in vivo, delays significantly the development of defective vasodilatation in rats with diabetes (14). These findings suggest that AGE-mediated NO quenching may contribute to acquired defects in vascular relaxation.

The enhanced proliferation of two subendothelial cell types, the vascular smooth muscle cell and the renal mesangial cell, have been linked to the accelerated vasculopathy and glomerulopathy that characterize long-standing diabetes mellitus (15). We hypothesize that the accumulation of subendothelial AGEs interferes with the antiproliferative activity of NO, resulting in myointimal and mesangial proliferation. In the present study, model cell culture systems were used to address the possibility that subendothelial AGEs functionally inactivate the antiproliferative effects of NO. We have confirmed that NO 
displays potent cytostatic effects in different mesenchymal cell types, and furthermore demonstrate that AGE-modified matrix proteins specifically block the antiproliferative effect of NO on vascular smooth muscle cells and kidney mesangial cells.

\section{Methods}

Reagents. BSA and glucose-6-phosphate were obtained from Sigma Chemical Co. (St. Louis, MO). Rat tail tendon collagen (type I) was from Collaborative Research, Inc. (Bedford, MA). $N$-acetyl- D,Lpenicillamine was purchased from Aldrich Chemical Co. (Milwaukee, WI). AGE-albumin was prepared by incubating albumin $(50 \mathrm{mg} / \mathrm{ml})$ with $0.5 \mathrm{M}$ glucose-6-phosphate in $0.2 \mathrm{M} \mathrm{Na} / \mathrm{PO}_{4}$ buffer ( $\mathrm{pH} \mathrm{7.4)} \mathrm{for}$ $60 \mathrm{~d}$ (14). Collagen solutions (at neutral $\mathrm{pH}$ ) were first microfuged for $15 \mathrm{~min}$ to remove insoluble material before incubation with glucose-6-phosphate. AGE-collagen was synthesized by incubating collagen $\left(5 \mathrm{mg} / \mathrm{ml}\right.$ ) with $0.5 \mathrm{M}$ glucose-6-phosphate in $0.2 \mathrm{M} \mathrm{Na} / \mathrm{PO}_{4}$ buffer ( $\mathrm{pH} 7.4$ ) for $60 \mathrm{~d}$. Glucose-6-phosphate was selected as the glycosylating sugar because the 6-phosphate shifts the anomerization equilibrium toward the reactive, open-chain form of the sugar (16). All incubations were performed under sterile conditions, in the dark, and at $37^{\circ} \mathrm{C}$. Samples were dialyzed extensively against PBS before analysis.

$S$-nitroso- $N$-acetyl-D,L-penicillamine (SNAP) was synthesized by reaction of $\mathrm{NaNO}_{2}$ and $\mathrm{N}$-acetyl-D,L-penicillamine following the method of Field et al. (17). Chemical purity and structural identity were established by melting point determination (measured value: $154.3^{\circ} \mathrm{C}$; reported value: $152-154^{\circ} \mathrm{C}[17]$ ), and by nuclear magnetic resonance spectroscopy.

Protein analyses. Albumin concentration was determined by the Bradford method (18) using BSA as a standard. Collagen amounts were determined by hydroxyproline assay as described by Edwards and O'Brien (19). The progress of AGE modification in vitro was determined by characteristic spectroscopic changes (optical absorbance at $350 \mathrm{~nm}$ and fluorescence emission at $460 \mathrm{~nm}$ following excitation at $390 \mathrm{~nm}$ ). AGE content was determined by ELISA using a specific anti-AGE antibody (20). In this immunoassay, $1 \mathrm{U}$ of AGE activity is defined as the amount of antibody-reactive material that is equivalent to $1 \mu \mathrm{g}$ of an AGE-BSA standard (20). The AGE content of the proteins used in cell cultures were as follows: AGE-BSA, $1 \mathrm{U} \mu \mathrm{g}^{-1}$; AGE-

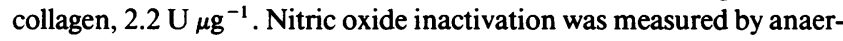
obic incubation of $200-\mu \mathrm{l}$ aliquots of test protein solutions with $50 \mu \mathrm{l}$ of authentic NO (12.5 nmol) prepared by dilution of an NO saturated standard solution (Matheson Gas Products, Inc., Bridgeport, NJ) (14). At the end of a 5-min incubation period, the remaining NO activity was determined spectroscopically. AGE-BSA was determined to inactivate

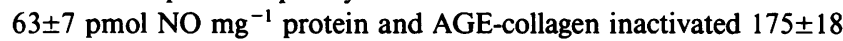
pmol NO $\mathrm{mg}^{-1}$ protein. The control (unmodified) BSA or collagen

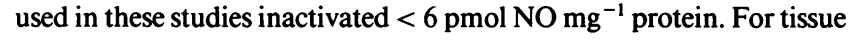
culture studies, protein samples were filter sterilized and analyzed by the Limulus amebocyte assay (Whittaker Bioproducts, Walkersville, MD) to ensure the absence of contaminating endotoxin (21).

Cell culture studies. The murine 3T6 fibroblast cell line was cultured in medium consisting of DME supplemented with $10 \%$ FCS and gentamicin $(50 \mu \mathrm{g} / \mathrm{ml})$. For the assay of mitogenesis, $\sim 300$ cells per well were seeded onto 96-well flat-bottom microtitre plates in a vol of $0.1 \mathrm{ml}$ ( corresponding to a plating density of 80 cells $/ \mathrm{mm}^{2}$ ). After $48 \mathrm{~h}$ of growth, culture medium was replaced with fresh medium consisting of DME supplemented with $1 \%$ FCS and dilutions of BSA or AGEBSA as indicated. Sterile aliquots of SNAP (freshly dissolved and diluted in PBS) were added to wells and incubation continued for $24 \mathrm{~h}$. Cultures then were supplemented with $20 \mu \mathrm{l}$ of PBS containing $1 \mu \mathrm{Ci}$ of $\left[{ }^{3} \mathrm{H}\right]$ methyl-thymidine ( $2 \mathrm{Ci} \mathrm{mmol}^{-1}$, New England Nuclear, Boston, MA). After a 24-h labeling period, thymidine incorporation was terminated by freezing whole cultures at $-20^{\circ}$. Cells then were lysed by freeze-thawing and the amount of $\left[{ }^{3} \mathrm{H}\right]$ thymidine incorporated into
DNA was measured by collecting cell lysates onto glass fiber filters ( $\mathrm{PhD}$ cell harvester; Cambridge Technology, Inc., Watertown, MA) and analyzing radioactivity by liquid scintillation spectrometry. For the 3T6 fibroblast studies, $\left[{ }^{3} \mathrm{H}\right]$ thymidine is expressed as total incorporated cpm per well. All assays were performed in triplicate and data points reflect two to three independent determinations.

Rat aortic smooth muscle cells were obtained from Drs. Richard Lappin and David Hajjar (Cornell University Medical College, New York). Smooth muscle cells were isolated from aortic explants obtained from Fisher 344 rats and assessed for purity following established protocols (22). Cells were grown in DME supplemented with $10 \% \mathrm{FCS}$ and $50 \mu \mathrm{g} / \mathrm{ml}$ gentamicin and used between the 4th and 11 th passages. Murine glomerular mesangial cells were the kind gift of Dr. Lilliane Striker (National Institutes of Health, Bethesda, MD). These cells were established from glomeruli isolated from normal 4-wk-old mice (C57B1 / 6JxSJL/J) and assessed for phenotypic stability as described (23). Cells were cultured in DME/10\% FCS and gentamicin and utilized between passages 26 and 36 .

96-well, flat-bottom microtitre plates were coated with unmodified or AGE-modified collagen by adding $0.1 \mathrm{ml}$ of the appropriate collagen dilution (in sterile PBS) to wells and allowing the solution to air dry overnight in a laminar flow hood (24). The collagen-coated wells were washed gently with PBS and the washed material was subjected to hydroxyproline assay to determine the efficiency of collagen adsorption (19). An adsorption efficiency of $>95 \%$ was observed for both unmodified and AGE-modified collagen over the range of collagen concentrations that were used in this study.

Vascular smooth muscle and mesangial cells were plated onto collagen-coated wells at a density of 260 cells $/ \mathrm{mm}^{2}$. Sterile aliquots of freshly prepared SNAP were added in media containing DME and $10 \%$ FCS, followed by $2 \mu \mathrm{Ci}$ aliquots of $\left[{ }^{3} \mathrm{H}\right]$ methyl-thymidine $(86 \mathrm{Ci}$ $\mathrm{mmol}^{-1}$ ). Incubation was continued for $40-48 \mathrm{~h}$. At the end of this time, the cell supernatants were removed and wells were filled with 75 $\mu \mathrm{l}$ of trypsin-EDTA (Gibco Laboratories, Grand Island, NY) before freezing and cell harvesting as described above.

For smooth muscle and mesangial cell growth, data are expressed as percent $\left[{ }^{3} \mathrm{H}\right]$ thymidine incorporation relative to control cell incubations which contained no SNAP. In control incubations, total thymidine incorporation ranged from 1 to $3 \times 10^{4} \mathrm{cpm} /$ well for aortic smooth muscle cells and $2.5-6 \times 10^{4} \mathrm{cpm} /$ well for mesangial cells. Cell toxicity was assessed throughout the course of incubation by observing for cellular detachment and enumerating detached cells.

\section{Results}

Experimental studies of the cellular effects of NO have used a variety of cell types and NO sources. For initial investigations of NO-induced cytostasis, we selected a murine fibroblast, the $3 \mathrm{~T} 6$ cell, as a model mesenchymal cell type. This immortalized cell line proliferates rapidly after serum-deprived growth arrest and provides a sensitive indicator of the presence of growth stimulatory or growth inhibitory mediators (25).

Nitric oxide has a short half-life in biological fluid $(<5 \mathrm{~s})$, and the introduction of a defined, continuous source of NO into cell culture systems has been problematic $(7,26)$. Experimental sources of NO have included co-cultured endothelial cells and exogenously added pro-drugs that form NO either spontaneously or after chemical reduction. These agents include the nitroglycerin derivatives, nitroprusside, and $S$-nitroso- $N$-acetylpenicillamine. $S$-nitroso- $N$-acetylpenicillamine was selected as a stable, chemical source of NO for these studies. In contrast to nitroglycerin derivatives, SNAP does not require intracellular reduction to produce $\mathrm{NO}$, and unlike ni- 


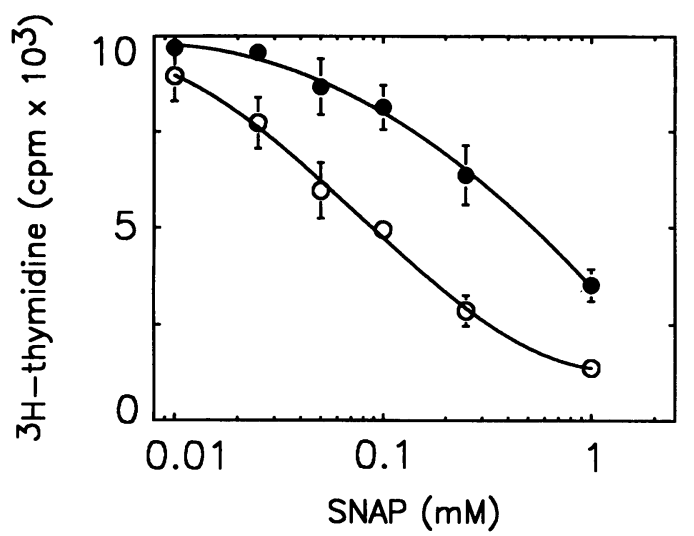

Figure 1. Dose-dependent inhibition of $\left[{ }^{3} \mathrm{H}\right]$ thymidine incorporation in murine $3 \mathrm{~T} 6$ fibroblasts by SNAP. (O) Cell cultures supplemented with BSA $(15 \mu \mathrm{M})$. (•) Cell cultures supplemented with AGE-BSA $(15 \mu \mathrm{M})$. Each point represents the mean \pm SEM of six wells. Data are representative of three independent determinations. Standard error bars are not shown for data points in which the width of the error bar is less than the width of the symbol.

troprusside, it does not generate potentially toxic cyanide or thiocyanate derivatives (26). Previous studies also have established the utility of SNAP as an NO-generator in model biological systems. SNAP slowly generates NO in aqueous media, stimulates intracellular cGMP production, and inhibits DNA synthesis without damaging cells or inactivating serum mitogens $(9,10,27)$.

Subconfluent murine fibroblasts (3T6 cells) were cultured in complete media for $48 \mathrm{~h}$. Medium then was changed to DME $/ 1 \%$ FCS containing different amounts of unmodified or AGE-modified BSA and increasing doses of SNAP. S-Nitroso$N$-acetylpenicillamine was found to inhibit $\left[{ }^{3} \mathrm{H}\right]$ thymidine incorporation in a dose-dependent fashion (Fig. 1). In the presence of $1 \mathrm{mg} / \mathrm{ml}$ of BSA $(15 \mu \mathrm{M})$, SNAP showed a dose-dependent inhibitory effect with an $\mathrm{IC}_{50}(100 \mu \mathrm{M})$ identical to that reported previously for murine fibroblasts (27). Of significance, culture of cells with AGE-modified BSA in place of control BSA resulted in a 0.5 log-fold shift in the dose-response curve to SNAP $\left(\mathrm{IC}_{50}: 100 \mu \mathrm{M} \rightarrow 500 \mu \mathrm{M}\right.$ ). AGE-BSA, by itself, displayed neither growth promoting nor growth-inhibiting effects in the concentration range used in these studies (1$100 \mu \mathrm{M})$.

The interaction between NO and AGEs in cell culture then was studied as a function of AGE concentration. As shown in Fig. 2 for a low and a high growth-inhibitory concentration of SNAP, AGE-BSA was observed to selectively spare the antimitogenic effect of SNAP. At the highest concentration, control (unmodified) BSA had only a small effect on NO-induced cytostasis. These experiments indicate that soluble, AGE-modified BSA inhibits the antiproliferative effect of exogenous NO in a model cell culture system. These results are consistent with the previously described chemical inactivation of NO by AGEderivatives (14).

To define more carefully the interaction of NO with representative tissue AGEs and cellular systems in vivo, we studied the cytostatic effect of NO on two primary cell types: aortic smooth muscle cells and renal mesangial cells. The abnormal, subendothelial proliferation of these cell types has been linked

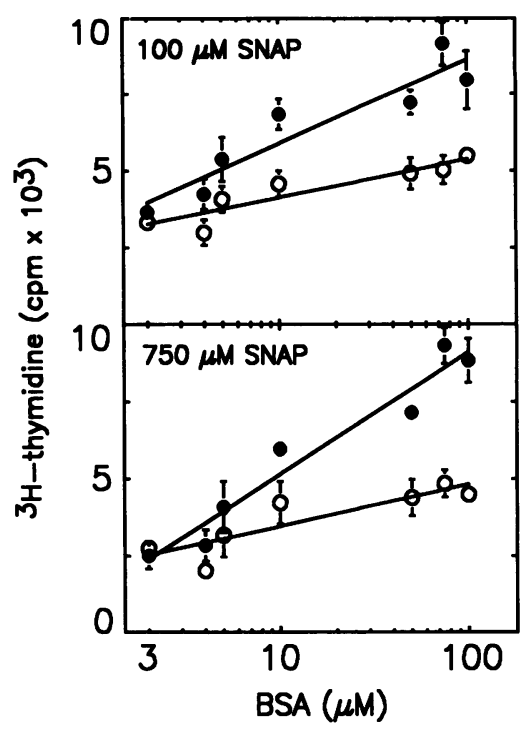

Figure 2. Effect of BSA and AGE-BSA concentration on NO-induced cytostasis of $3 \mathrm{~T} 6$ fibroblasts at two fixed concentrations of SNAP $(100 \mu \mathrm{M}$ and $750 \mu \mathrm{M})$. Cell cultures were supplemented with BSA (o) or with AGE-BSA (•). Each point represents the mean \pm SEM of six wells. Data are representative of two independent determinations. Standard error bars are not shown for data points in which the width of the error bar is less than the width of the symbol. to the accelerated vascular and renal pathology of diabetes mellitus (15). To more closely approximate the in situ environment of these cells, we studied the mitogenic response of cells cultured on an immobilized collagen matrix. 96-well flat-bottom plates were coated with either control (unmodified) colla-

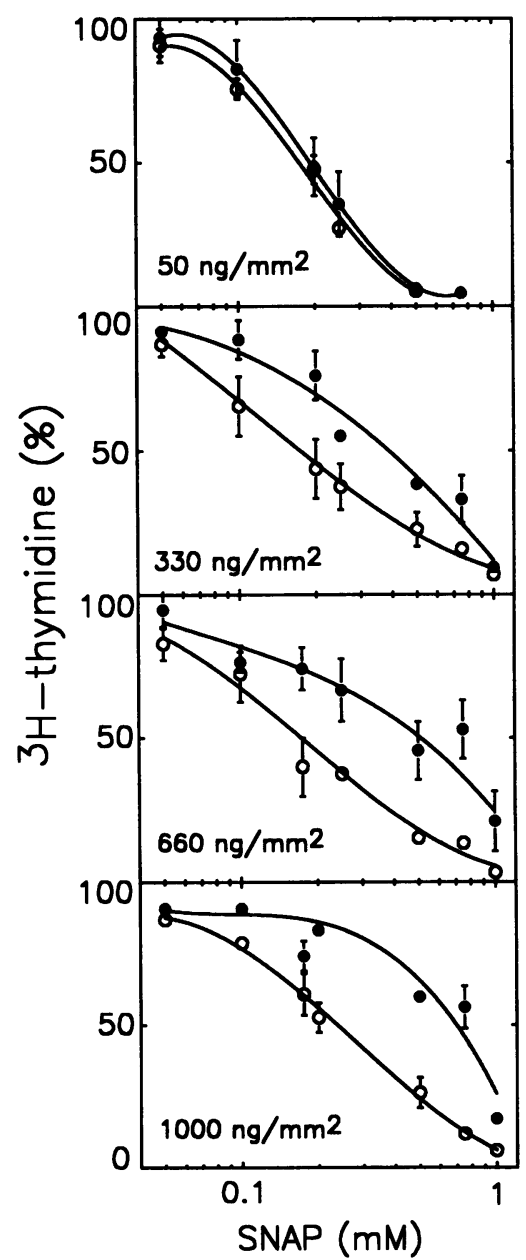

Figure 3. Dose-dependent inhibition of aortic smooth muscle cell mitogenesis by SNAP in the presence of four concentrations of control (O) and AGE-modified $(\bullet)$ collagen. Percent $\left[{ }^{3} \mathrm{H}\right]$ thymidine incorporation is relative to control incubations which contained no added SNAP. Total $\left[{ }^{3} \mathrm{H}\right]$ thymidine incorporation in control wells ranged from 1 to 3 $\times 10^{4} \mathrm{cpm}$ in different experiments. Each point shows the mean \pm SEM of two to three independent determinations, each representing data from triplicate wells. Standard error bars are not shown for data points in which the width of the error bar is less than the width of the symbol. 
gen or AGE-modified collagen. Vascular smooth muscle cells then were plated onto the collagen matrix and increasing doses of SNAP added. As in the case of the 3T6 cells, SNAP inhibited smooth muscle cell $\left[{ }^{3} \mathrm{H}\right]$ thymidine incorporation in a dose-dependent fashion (Fig. 3). When grown on $50 \mathrm{ng} / \mathrm{mm}^{2}$ of control or AGE-modified collagen, smooth muscle cells showed no difference in their sensitivity to the cytostatic action of NO

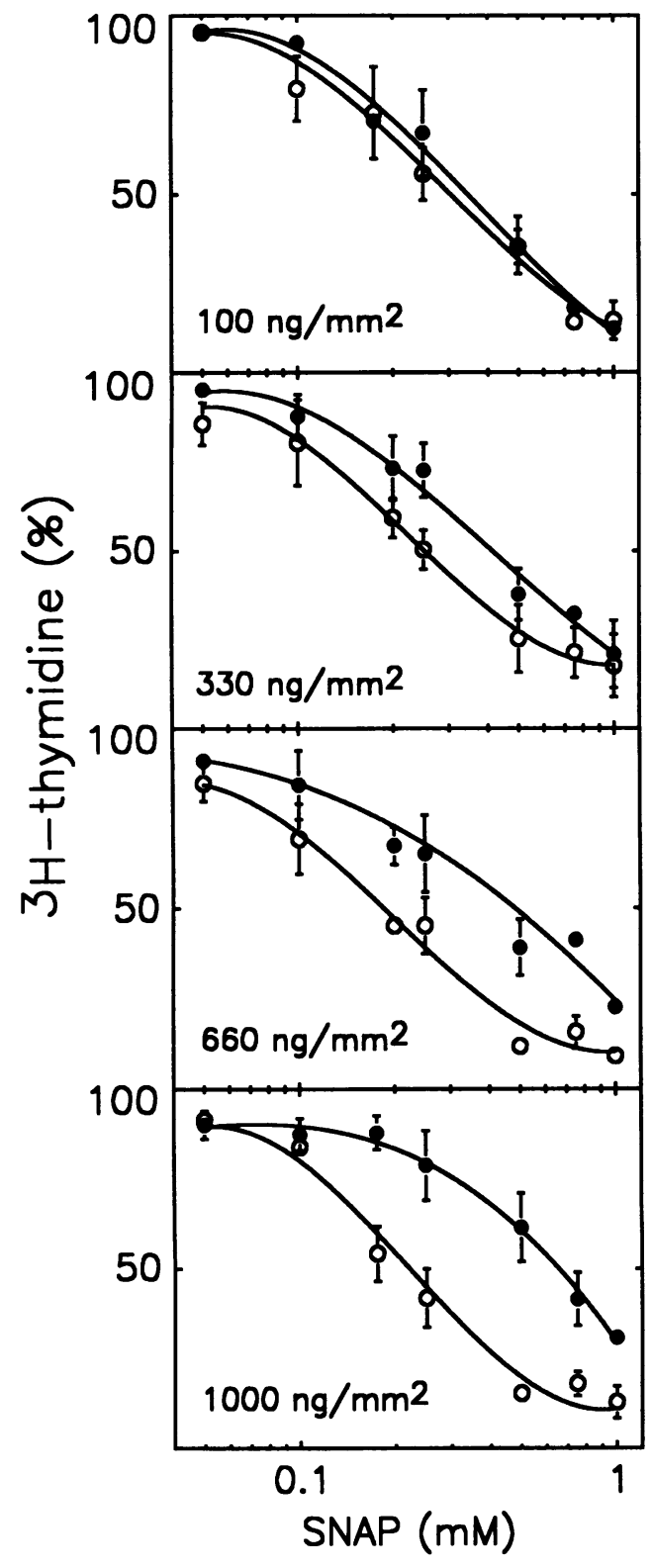

Figure 4. Dose-dependent inhibition of murine mesangial cell mitogenesis by SNAP in the presence of four concentrations of control $(0)$ and AGE-modified $(\bullet)$ collagen. Percent $\left[{ }^{3} \mathrm{H}\right]$ thymidine incorporation is relative to control incubations containing no added SNAP. Total $\left[{ }^{3} \mathrm{H}\right]$ thymidine incorporation in control wells ranged from 2.5 to $6 \times 10^{4} \mathrm{cpm}$ in different experiments. Each point shows the mean \pm SEM of two to three independent determinations, each representing data from triplicate wells. Standard error bars are not shown for data points in which the width of the error bar is less than the width of the symbol.
$\left(\mathrm{IC}_{50}=150 \mu \mathrm{M}\right.$ SNAP $)$. With increasing amounts of AGE-collagen however, a significant and concentration-dependent difference in the antiproliferative effect of $\mathrm{NO}$ was observed. The $\mathrm{IC}_{50}$ increased from $150 \mu \mathrm{M}$ at $50 \mathrm{ng} / \mathrm{mm}^{2}$ of AGE-collagen to $700 \mu \mathrm{M}$ at $1,000 \mathrm{ng} / \mathrm{mm}^{2}$ of AGE-collagen. AGE-collagen itself neither enhanced nor inhibited cellular proliferation in the amounts that were present in the culture wells. In agreement with prior studies $(9,10,27)$, NO-induced cytostasis was not observed to be accompanied by any apparent cytotoxic effects.

In patients with diabetes mellitus, the glomerular basement membrane accumulates high levels of collagen-bound AGEs (2). Subendothelial mesangial cell hyperplasia is an early and characteristic lesion in diabetic glomerulopathy (15). It was of interest, therefore, to determine whether AGE-modified collagen might similarly prevent the cytostatic effect of NO on isolated renal mesangial cells. As in the case of aortic smooth muscle cells, mesangial cells plated on different concentrations of AGE-collagen were found to be less sensitive to NO-induced cytostasis (Fig. 4). The $\mathrm{IC}_{50}$ of SNAP increased from $320 \mu \mathrm{M}$ at $100 \mathrm{ng} / \mathrm{mm}^{2}$ of AGE-collagen to $680 \mu \mathrm{M}$ at $1,000 \mathrm{ng} / \mathrm{mm}^{2}$ of AGE-collagen.

\section{Discussion}

Endothelium-derived NO is a potent vasodilator that exerts significant homeostatic and antiproliferative effects on a variety of cell types $(8-10,27)$. In particular, the cytostatic action of NO has been proposed to play an important role in maintaining the mitogenic quiescence of subendothelial vascular smooth muscle cells (9). Experimental damage or removal of endothelium is associated with proliferation of underlying smooth muscle cells. This leads to myointimal proliferation, often considered the "hallmark" lesion of atherosclerosis (13). Several renal glomerulopathies, such as the diabetic and hyperlipidemic, also are associated with a mesenchymal (mesangial cell) hyperplasia that may occur by processes similar to those involving aortic smooth muscle cells (15).

Patients with long-standing diabetes mellitus have a markedly increased tendency toward developing atherosclerotic vascular disease $(2,28)$. An important consequence of chronic hyperglycemia is an increase in the formation of protein-bound AGEs. The accumulation of tissue and basement membrane AGEs is one of several biochemical abnormalities that may promote vascular wall dysfunction and atherogenesis $(2,13)$. Recent studies indicate that diabetic patients also have high circulating levels of AGE-peptides. In patients with diabetes and chronic renal failure, a group subject to a rapidly progressive vasculopathy, serum AGE levels have been determined to be eightfold higher than in normal patients, and almost fourfold higher than in diabetic patients with normal renal function $(29,30)$. Circulating AGEs enter the subendothelial matrix by direct infiltration or by endothelial cell-mediated transcytosis (31). AGEs may then interact with specific monocyte, endothelial cell, and mesangial cell receptors $(24,31,32)$. This results in a variety of responses including the release of cytokines such as interleukin-1, tumor necrosis factor, and platelet-derived growth factor $(33,34)$. These mediators produce autocrine and paracrine effects that ultimately promote the development of both atherosclerotic and glomerular lesions.

The present study demonstrates that at low levels, matrix- 
bound AGEs contribute directly to mesenchymal cell proliferation by inactivating endothelium-derived NO and eliminating its cytostatic activity. Both vascular smooth muscle and renal mesangial cells show decreased sensitivity to NO when cultured on an AGE-modified matrix. These data suggest that the AGE-mediated inactivation of NO represents an important mechanism in the development of the proliferative vascular and renal lesions of diabetes.

Previous studies have shown that the inactivation of NO by AGEs proceeds via a direct chemical reaction (14). Nitric oxide may react directly with the unsaturated pyrrole or furan moieties that appear to be common structures in advanced glycosylation chemistry $(1,3)$. The reaction between NO and AGEs does not appear to proceed by nitrosation however ( $\mathrm{Bu}-$ cala, R., unpublished observations), and may instead involve radical-mediated quenching. Model biosynthetic pathways for AGE formation suggest the occurrence of several oxidation-reduction steps that could create reactive, radical centers $(1,3$, 35-37). Of significance, the in vitro time course of AGEmediated quenching appears to parallel the formation of AGE-derived free radicals, as measured by electron spin resonance (38).

The precise mechanism of the NO-induced cytostasis was not addressed in this study. Studies of the intracellular effects of NO have focused on its ability to increase cGMP levels by activating guanylate cyclase and in many cell types, the antimitogenic activity of NO can be mimicked by exogenously administered 8-bromo-cGMP $(8,9)$. Nitric oxide also is cytostatic in cell types lacking soluble guanylate cyclase however (27), suggesting that other pathways such as ADP-ribosylation may be important for this effect (39).

In conclusion, the present study has demonstrated that both soluble and matrix-bound AGEs are potent inhibitors of NO-mediated cytostasis. Of significance, collagen-bound AGEs were found to spare the cytostatic effect of NO in cultured aortic smooth muscle and renal mesangial cells. These data implicate tissue AGEs as important modulators of NO activity in vivo, and suggest a novel, common pathway for the evolution of the proliferative vascular and glomerular lesions present in diabetes mellitus.

\section{Acknowledgments}

We are grateful to Drs. H. Vlassara, L. Striker, and G. Striker for helpful discussions. We also thank Dr. R. Lappin for assistance in smooth muscle cell isolation and Dr. P. Ulrich for assistance with the melting point and nuclear magnetic resonance analyses.

This work was supported by the American Diabetes Association (R. Bucala) and National Institutes of Health grant DK19655-15 (A. Cerami).

\section{References}

1. Njoroge, F. G., and V. M. Monnier. 1989. The chemistry of the Maillard reaction under physiological conditions: a review. Prog. Clin. Biol. Res. 304:85107.

2. Brownlee, M., A. Cerami, and H. Vlassara. 1988. Advanced glycosylation endproducts in tissue and the biochemical basis of diabetic complications. $N$. Engl. J. Med. 318:1315-1321.

3. Ledl, F., and E. Schleicher. 1990. New aspects of the Maillard reaction in foods and in the human body. Angew. Chem. Int. Ed. Engl. 6:565-706.
4. Furchgott, R. F. 1984. The role of endothelium in the responses of vascular smooth muscle to drugs. Annu. Rev. Pharmacol. Toxicol. 24:175-197.

5. Ignarro, L. J., G. M. Buga, K. S. Wood, R. E. Byrns, and G. Chaudhuri. 1987. Endothelium-derived relaxing factor produced and released from artery and vein is nitric oxide. Proc. Natl. Acad. Sci. USA. 84:9265-9269.

6. Palmer, R. M. J., A. G. Ferrige, and S. Moncada. 1987. Nitric oxide release accounts for the biological activity of endothelium-derived relaxing factor. $\mathrm{Na}$ ture (Lond.). 327:524-526.

7. Moncada, S., R. M. J. Palmer, and E. A. Higgs. 1991. Nitric oxide: physiology, pathophysiology, and pharmacology. Pharmacol. Rev. 43:109-142.

8. Shultz, P. J., A. E. Schore, and L. Raij. 1990. Effects of endothelium-derived relaxing factor and nitric oxide on rat mesangial cells. Am. J. Physiol. 258:F162-167.

9. Garg, U. C., and A. Hassid. 1989. Nitric oxide-generating vasodilators and 8-bromo-cyclic guanosine monophosphate inhibit mitogenesis and proliferation of cultured rat vascular smooth muscle cells. J. Clin. Invest. 83:1774-1777.

10. Garg, U. C., and A. Hassid. 1989. Inhibition of rat mesangial cell mitogenesis by nitric oxide-generating vasodilators. Am. J. Physiol. 257:F60-F66.

11. Aisaka, K., S. G. Gross, O. W. Griffith, and R. Levi. 1989. NG-Methylarginine, an inhibitor of endothelium-derived nitric oxide synthesis, is a potent pressor agent in the guinea pig: does nitric oxide regulate blood pressure in vivo? Biochem. Biophys. Res. Commun. 160:881-886.

12. Rees, D. D., R. M. Palmer, and S. Moncada. 1989. Effects of endothelium-derived nitric oxide in the regulation of blood pressure. Proc. Natl. Acad. Sci. USA. 86:3375-3378.

13. Ross, R. 1986. The pathogenesis of atherosclerosis. An update. N. Engl. J. Med. 314:488-500.

14. Bucala, R., K. J. Tracey, and A. Cerami. 1991. Advanced glycosylation products quench nitric oxide and mediate defective endothelium-dependent vasodilatation in experimental diabetes. J. Clin. Invest. 87:432-438.

15. Steffes, M. W., and S. M. Mauer. 1990. Pathophysiology of renal complications. In Diabetes Mellitus, Theory and Practice. H. Rifkin and D. Porte, editors. Elsevier Science Publishing Co., Inc., New York. 257-263.

16. Schwimmer, S., and H. S. Olcott. 1953. Reaction between glycine and hexose phosphates. J. Am. Chem. Soc. 75:4855.

17. Field, L., R. V. Dilts, R. Ravichandran, P. G. Lenhert, and G. E. Carnahan. 1978. An unusually stable thionitrite from $N$-acetyl-D,L-penicillamine: Xray crystal and molecular structure of 2-(acetylamino)-2-carboxy-1,1-dimethylethyl thionitrite. J. Chem. Soc. Chem. Commun. I:249-250.

18. Bradford, M. M. 1976. A rapid and sensitive method for the quantitation of microgram quantities of protein utilizing the principle of protein-dye binding. Anal. Biochem. 72:248-254.

19. Edwards, C. A., and W. D. O'Brien, Jr. 1980. Modified assay for determination of hydroxyproline in a tissue hydrolysate. Clin. Chim. Acta. 104:161-167.

20. Makita, Z., H. Vlassara, A. Cerami, and R. Bucala. 1992. Immunochemical detection of advanced glycosylation end products in vivo. J. Biol. Chem. 267:5133-5138.

21. Young, N. S., J. Levin, and R. A. Prendergast. 1972. An invertebrate coagulation system activated by endotoxin: evidence for an enzymatic mechanism. J. Clin. Invest. 51:1790-1797.

22. Hariri, R. J., D. P. Hajjar, D. Coletti, D. R. Alonso, M. E. Weksler, and E. Rabellino. 1988. Aging and atherosclerosis, cell cycle kinetics of young and old arterial smooth muscle cells. Am. J. Pathol. 131:132-136.

23. MacKay, K., L. J. Striker, K. Kimata, E. Peten, Y. Yamada, and G. E. Striker. 1991. Glomerular epithelial, mesangial, and endothelial cell lines from transgenic mice. Kidney Int. 33:677-684.

24. Skolnik, E. Y., Z. Yang, Z. Makita, S. Radoff, M. Kirstein, and H. Vlassara. 1991. Human and rat mesangial cell receptors for glucose-modified proteins: potential role in kidney tissue remodelling and diabetic nephropathy. $J$. Exp. Med. 174:931-939.

25. Bucala, R., C. Ritchlin, R. Winchester, and A. Cerami. 1991. Constitutive production of inflammatory and mitogenic cytokines by rheumatoid synovial fibroblasts. J. Exp. Med. 173:569-574.

26. Feelisch, M. 1991. The biochemical pathways of nitric oxide formation from nitrosovasodilators: appropriate choice of exogenous NO donors and aspects of preparation and handling of aqueous NO solution. J. Cardiovasc. Pharmacol. 17(Suppl. 3):S25-S33.

27. Garg, U. C., and A. Hassid. 1990. Nitric oxide-generating vasodilators inhibit mitogenesis and proliferation of Balb/c 3T3 fibroblasts by a cyclic GMPindependent mechanism. Biochem. Biophys. Res. Commun. 171:474-479.

28. Steinberg, D., S. Parthasarathy, T. E. Carew, J. C. Khoo, and J. L. Witztum. 1989. Beyond cholesterol. Modifications of low-density lipoprotein that increase its atherogenicity. N. Engl. J. Med. 320:915-924.

29. Sell, D. R., and V. M. Monnier. 1990. End-stage renal disease and diabetes catalyze the formation of a pentose-derived crosslink from aging human collagen. J. Clin. Invest. 85:380-384.

30. Makita, Z., S. Radoff, E. J. Rayfield, Z. Yang, E. Skolnik, V. Delaney, 
E. A. Friedman, A. Cerami, and H. Vlassara. 1991. Advanced glycosylation end products in patients with diabetic nephropathy. $N$. Engl. J. Med. 325:836-842.

31. Esposito, C., H. Gerlach, J. Brett, D. Stern, and H. Vlassara. 1989. Endothelial receptor-mediated binding of glucose-modified albumin is associated with increased monolayer permeability and modulation of cell surface coagulant properties. J. Exp. Med. 170:1387-1407.

32. Vlassara, H., M. Brownlee, and A. Cerami. 1985. High-affinity-receptormediated uptake and degradation of glucose-modified proteins: a potential mechanism for the removal of senescent macromolecules. Proc. Natl. Acad. Sci. USA. 82:5588-5592.

33. Vlassara, H., M. Brownlee, K. R. Manogue, C. A. Dinarello, and A. Pasagian. 1988. Cachectin/TNF and IL-1 induced by glucose-modified proteins role in normal tissue remodelling. Science (Wash. DC). 240:1546-1548.

34. Kirstein, M., J. Brett, S. Radoff, S. Ogawa, D. Stern, and H. Vlassara. 1990. Advanced protein glycosylation induces transendothelial human mono- cyte chemotaxis and secretion of platelet-derived growth factor: role in vascular disease of diabetes and aging. Proc. Natl. Acad. Sci. USA. 87:9010-9014.

35. Pongor, S., P. C. Ulrich, F. A. Bencsath, and A. Cerami. 1984. Aging of proteins: isolation and identification of a fluorescent chromophore from the reaction of polypeptides with glucose. Proc. Natl. Acad. Sci. USA. 81:2684-2688.

36. Ahmed, M. U., J. A. Dunn, M. D. Walla, S. R. Thorpe, and J. W. Baynes. 1988. Oxidative degradation of glucose adducts to protein. J. Biol. Chem. 263:8816-8821.

37. Grandhee, S. K., and V. M. Monnier. 1991. Mechanism of formation of the Maillard protein cross-link pentosidine. Glucose, fructose, and ascorbate as pentosidine precursors. J. Biol. Chem. 266:11649-11653.

38. Namiki, M., and T. Hayashi. 1981. Formation of novel free radical products in an early stage of Maillard reaction. Prog. Food \& Nutr. Sci. 5:81-91.

39. Brune, B., and E. G. Lapentina. 1989. Activation of a cytosolic ADP-ribosyltransferase by nitric oxide-generating agents. J. Biol. Chem. 264:8455-8458. 